\title{
Factors associated with dairy calf health in automated feeding systems in the Upper Midwest United States
}

\author{
M. W. Jorgensen, ${ }^{*}$ A. Adams-Progar, ${ }^{*}$ A. M. de Passillé,† J. Rushen,† S. M. Godden,‡ H. Chester-Jones, \\ and M. I. Endres*1 \\ ${ }^{*}$ Department of Animal Science, University of Minnesota, St. Paul 55108 \\ †Animal Welfare Program, University of British Columbia, Vancouver, BC, Canada V6T 1 Z4 \\ ‡Department of Veterinary Population Medicine, University of Minnesota, St. Paul 55108
}

\section{ABSTRACT}

Automated calf feeding systems are becoming more common on US dairy farms. The objective of this study was to evaluate calf health in these systems and to identify risk factors associated with adverse health outcomes on farms in the Upper Midwest United States. Over an 18-mo period on bimonthly farm visits to 38 farms, calves $(\mathrm{n}=10,179)$ were scored for attitude, ear, eye, and nasal health, as well as evidence of diarrhea (hide dirtiness score of perianal region, underside of the tail, and tailhead). For all health score categories, a score of 0 represented an apparently healthy animal. Rectal temperatures were taken in calves scoring a $\geq 2$ in any category, and those with a temperature $>39.4^{\circ} \mathrm{C}$ were categorized as having a fever $(\mathrm{n}=550)$. Associations were determined between farm-level variables and health scores to identify risk factors for higher (worse) scores. All health outcomes were associated with season of measurement, with fall and winter seasons increasing the odds of a high health score or detected fever. High bacterial counts measured in the milk or milk replacer were associated with increased odds for higher attitude and ear scores, and higher odds for calves having a detected fever. Higher peak milk allowance (L/d) was associated with lower hide dirtiness score, whereas a longer period of time (d) to reach peak milk allowance was associated with increased odds of higher scores for attitude, ear, eye, and hide dirtiness, as well as fever. Higher fat content in milk was associated with increased odds of high eye score. Less space per calf $\left(\mathrm{m}^{2} /\right.$ calf $)$ was associated with higher ear and eye scores, whereas larger group sizes were associated with increased odds of higher nasal score and decreased odds of higher hide dirtiness score. Rectangular pen shape was associated with decreased odds of higher eye score. Absence of a

Received December 21, 2016.

Accepted March 13, 2017.

${ }^{1}$ Corresponding author: miendres@umn.edu positive pressure ventilation tube was associated with increased odds of having a calf detected with a fever. Based on these results, we hypothesize that these factors could be managed to improve health outcomes for dairy calves on automated feeding systems.

Key words: dairy calf, automated feeder, health, welfare

\section{INTRODUCTION}

The period between birth and weaning represents a time of high risk for dairy calves; national survey results indicate that $6.0 \pm 0.7 \%$ of live-born calves die during this period (USDA, 2017). Infectious disease is a particularly high risk for calves, with enteric and respiratory infections being the most common cause of disease-related death (Svensson et al., 2006), and these diseases influence economic efficiency and long-term production in the dairy industry (Heinrichs et al., 2005). Because of the risk of spreading infection between animals, dairy calves in the United States are traditionally housed in individual pens or hutches to minimize physical contact (Callan and Garry, 2002). Although early studies found that calves housed individually had lower morbidity and mortality rates (Waltner-Toews et al., 1986b,c), later larger-scale, observational studies did not report better health in individually housed calves compared with those housed in small groups of 6 to 8 calves (e.g., Losinger and Heinrichs, 1997; Svensson et al., 2003). In addition, individual housing is increasingly criticized for restricting physical movement and social interaction of calves (Rushen et al., 2008) and an increasing number of farm operations are shifting toward group-housed systems.

Housing calves in groups increases the opportunity for social interaction and facilitates normal calf behaviors (Chua et al., 2002), and can affect the transition to solid feed, leading to better postweaning weight gains (de Paula Vieira et al., 2010; Costa et al., 2015; MillerCushon and DeVries, 2016). However, group housing 
presents its own challenges. Although group housing systems are not inherently worse for calf health than individual housing (e.g., Losinger and Heinrichs, 1997; Svensson et al., 2003), group size is an important factor. Calves housed in larger groups ( $>6$ to 8 calves) appear to be at higher risk for mortality and respiratory disease than those in small groups (Losinger and Heinrichs, 1997; Svensson et al., 2003; Svensson and Liberg, 2006).

Automated feeding systems are becoming increasingly popular in the Upper Midwest United States as a tool for managing calves in group-housed systems. These computer-controlled feeding systems provide operators with individual calf data, flexibility in diet and weaning management, and have been shown to significantly affect manual calf-care labor (Kung et al., 1997; Kack and Ziemerink, 2010). Although popular in Europe, these systems are relatively new to the United States and little is known about the manner in which they are employed on dairy farms in the United States. It is critical to better understand how key management practices, facility design characteristics, and environmental factors may affect calf health. The objectives of this study were to document the health status of calves on farms using automated feeding systems and to investigate the association of management factors with calf health.

\section{MATERIALS AND METHODS}

\section{Data Collection}

This study was conducted on 38 farms in Minnesota, northwest Iowa, and Wisconsin using automated milk feeders for preweaned calves. These farms used FörsterTechnik (Engen, Germany) automated calf feeders, with the exception of 2 farms: 1 used a Holm \& Laue (Westerrönfeld, Germany), the other an Urban feeder (Wüsting, Germany). Farms were randomly selected from the total known population of automated feeder farms in the region at the time of selection (64 facilities) as identified by extension staff, equipment dealers, veterinarians, consultants, and producers. The number of farms selected was determined to be the number logistically feasible within the established data collection schedule. However, once selected for potential inclusion in the study, participation by individual producers was voluntary. Each farm was visited up to 8 times, approximately every $60 \mathrm{~d}$ (bimonthly), between November 2012 and May 2014. Data were collected through a combination of direct observation of the calves and their environment, along with an in-person interview with the farm operator using a questionnaire. The study was carried out in accordance with the recommendations of the Institutional Animal Care and Use Committee, and the protocol was approved by the committee. Consent was granted by the farm operators.

Measurements of calf barn and pen characteristics were recorded at the time of each visit and changes were noted if needed at each visit in addition to any changes in management practices. Barn characteristics included barn construction type (new or retrofitted), ventilation type (natural ventilation, mechanical ventilation), number and size of fans, and aspects of supplemental positive pressure ventilation tubes (diameter, outlet hole size, spacing and placement, and air inlet source) if present. At each visit, pen characteristics were recorded including pen size, group size, space per calf, and bedding type and depth. Bedding wetness was evaluated at 4 locations in each pen $(0=$ dry; $4=$ very wet; Canadian Dairy Research Project, 2011).

At each bimonthly visit, thermal conditions at a central location in each calf area were uploaded from temperature-humidity loggers (HOBO A23 Pro Series, Onset Corp., Bourne, MA), which recorded temperature and humidity hourly throughout the 18-mo study period. To maintain parsimony in the final models produced, calendar season was used as a comprehensive category incorporating temperature, humidity, photoperiod, and other environmental factors that vary significantly throughout the year. Seasons were defined as onset of the study to December 20, 2012 (fall 1), December 21, 2012, to March 20, 2013 (winter 1), March 21, 2013, to June 20, 2013 (spring 1), June 21, 2013, to September 20, 2013 (summer 1), September 21, 2013, to December 20, 2013 (fall 2), December 21, 2013, to March 20, 2014 (winter 2), and March 21 to May 20, 2014 (spring 2).

Calf health was evaluated within 2 calf pens on smaller farms (4 or fewer total pens; 33 farms) or in 3 pens (farms with 5 or more total pens; 5 farms) using a health scoring method adapted from McGuirk, University of Wisconsin (https://www.vetmed.wisc.edu/dms/ fapm/fapmtools/8calf/calf_health_scoring_chart.pdf). This method scored physical indicators of calf health status on a 0 to 4,0 to 3 , or 0 to 2 scale. For all health score categories, a score of 0 represented an apparently healthy animal. Attitude score in the current study was on a scale of 0 to 4 , with $0=$ active, $1=$ quiet/dull, $2=$ depressed, $3=$ nonresponsive, and $4=$ dead. Ear position (ear score) was on a scale of 0 to 4 with 0 = no ear droop, 1 = unilateral ear droop, $2=$ slight bilateral ear droop, $3=$ severe bilateral ear droop, and $4=$ head tilt. Ocular discharge (eye score) was on a scale of 0 to 3 , with $0=$ no discharge, $1=$ small amount of ocular discharge, $2=$ moderate amount of bilateral discharge, and $3=$ heavy ocular discharge. Nasal discharge (nasal score) was on a scale of 0 to 3 
with $0=$ normal serous discharge, $1=$ small amount of unilateral cloudy discharge, $2=$ bilateral, cloudy, or excessive discharge, and $3=$ copious bilateral mucopurulent discharge. Incidence of diarrhea was modified from the original McGuirk scoring method, and was measured using an assessment (hide dirtiness score) of the perianal region, underside of the tail, and tailhead of each calf and on a scale of 0 to 2 with $0=$ clean, $1=$ evidence of loose or abnormal fecal consistency, and $2=$ significant evidence of watery diarrhea. The relatively limited area scored increased the likelihood that the fecal material observed originated from the observed calf and decreased the likelihood that wet fecal material was from soiled bedding, but it must be acknowledged that some amount of fecal material could be from the environment. Rectal temperatures were taken on calves scoring $\geq 2$ on any health score category, and calves with a temperature $>39.4^{\circ} \mathrm{C}$ were categorized as having a fever. All calf health scores were measured by a single trained observer over the course of the study. Health scores were collected on 10,179 preweaned calves during the 18-mo study period, and farms reported a median calf population of 45 animals (range 7 to 300 ) during any one visit. However, because of missing values this total number was not always used. The number of observations is noted alongside each statistical model.

Colostrum management quality (success or failure of passive transfer) was evaluated by measuring serum total protein (STP) in a convenience sample of young calves. Blood samples were taken at the time of each visit from every clinically normal calf (up to 12 animals/farm per visit) between $24 \mathrm{~h}$ and $5 \mathrm{~d}$ of age. These samples were centrifuged and STP was measured from each sample using a handheld, analog light refractometer (model HR-200 ATC, AFAB Enterprises, Eustis, FL). The instrument was calibrated with distilled water before measuring STP of all samples collected that day. Results were described using 2 STP cut-points (5.0 and $5.2 \mathrm{~g} / \mathrm{dL}$ ), which have been identified as the most accurate for evaluating passive immune transfer in dairy calves (Calloway et al., 2002).

Milk or milk replacer (referred to as milk) samples (approximately 50-mL representative sample) were collected quarterly (on 5 of the visits) from both the automated feeder mixing tank (mixing tank) and the point of connection between the flexible dispensing tube or hose and the nipple (tube end) from each farm for bacterial analysis. These samples were immediately placed on ice and frozen as quickly as possible (within $6 \mathrm{~h}$ ). All milk samples were analyzed for SPC and coliform bacteria count at the University of Minnesota Veterinary Diagnostic Laboratory (St. Paul, MN). Samples were categorized as high or low bacterial contamination to delineate between those which fell under the recommended limits for SPC $(<100,000 \mathrm{cfu} / \mathrm{mL})$ and coliform contamination $(<10,000 \mathrm{cfu} / \mathrm{mL}$; McGuirk and Collins, 2004). Milk samples were also collected twice (in summer and winter) following a protocol identical to that for the mixing tank sample and analyzed for milk components (fat, protein, solids) using wet chemistry methods (AOAC method \#985.09; AOAC method \#930.29; SMEDP \#15.114, respectively). All component analysis was conducted by AgSource Laboratories (Marshfield, WI).

Farm management practices were collected via questionnaire at the study onset and included topics such as calving and neonate management, colostrum management, postnatal procedures (castration/dehorning), calf housing and bedding management, stocking and moving of animals, calf feeding and weaning practices, management and cleaning of the automated feeder equipment, and barn pest control. Changes to management practices were collected at the time of each visit.

\section{Statistical Analysis}

The amount of research is limited on the management and housing characteristics of herds that use automated calf feeding systems in the United States, which made power calculations for sample size difficult. Because of this, and to gain the clearest possible evaluation of these systems, the study enrolled the largest possible number of farms given the logistical constraints of data collection. Just under $60 \%$ of the total number of farms (64) using automated calf feeding systems in the region at the time of onset of the study were enrolled.

Descriptive Analysis. The means procedure (PROC MEANS, SAS 9.3, SAS Institute Inc., Cary, NC) was used to calculate means and standard deviations or medians and interquartile range (IQR). Variable skewness was visually assessed. For continuous variables that appeared normally distributed (maximum recorded air speed in the pen, time from birth to first colostrum feeding, amount of colostrum delivered at first feeding, STP, age at separation from the dam, age at grouping, age range of calves in the group pen, pen size, space allowed per calf, bedding depth, starting milk allowance, peak milk allowance, liquid diet percent fat, percent protein, and percent solids), means and standard deviations or ranges are reported. For continuous variables that appeared to be skewed in one direction (number of milking cows, number of calves, and bacterial contamination), median and IQR are reported. The frequency procedure (PROC FREQ, SAS 9.3) was used to report the distribution of categorical variables (breed, housing type, ventilation type, presence of positive pressure 
ventilation tubing, colostrum delivery method, stocking pattern, bedding type, bedding wetness, liquid diet type, and health score frequencies).

Risk Factor Analysis. Association between each of the variables measured on farm and the separate health score outcomes (attitude, ear, eye, nasal, hide dirtiness, and fever) was initially evaluated using a univariable model for screening (PROC GLIMMIX; SAS Institute Inc.). Farm, cohort (visit number) within farm, and pen within cohort within farm were fitted as random effects. No association was present between type of liquid diet fed - whole milk or milk replacer - and any of the variables tested; therefore type of liquid diet was not included in the final models.

A multivariable model (GLIMMIX; SAS Institute Inc.) for each health score outcome was developed from those variables identified as meeting a given criterion $(P<0.3)$ in the univariable analysis. Backward elimination was used to eliminate variables from the multivariable model until all remaining variables were significant $(P<0.05)$. In the multivariable models for attitude score, eye score, ear score, nasal score, and hide dirtiness score, the error distribution was multinomial and a cumulative logit link function was used. Because the fever category had only 2 outcomes (yes/ no), the error distribution of this model was binomial and a logit link function was used. Due to the hierarchical structure of random effects and distribution of the data in the multivariable analysis, models did not reach convergence when 2-way interaction terms were included, although different convergence methodologies (Laplace or Gauss-Hermite quadrature) were tried. Because parsimony of the models was a prerogative, these interactions were excluded although some effect modification may exist. Pearson correlation was used to compare explanatory variables and to identify issues with collinearity. In cases where 2 variables were highly correlated $(\mathrm{r}>0.7)$, the factor which was more likely to be biologically relevant was included in the model (e.g., the bacterial count for the feeder tube-end milk samples was included and the bacterial count for the feeder mixing tank was excluded from the model).

\section{RESULTS AND DISCUSSION}

\section{Descriptive Analysis}

Herd and Group Pen Management Characteristics. The 38 farms enrolled in this study varied widely and had a median milking herd size of 367 cows (range 60 to 3,000 ) and median calf population of 45 animals (range: 7 to 300) at a time. The majority of these operations $(61.1 \%)$ had only Holstein cattle, whereas the remainder had both Holsteins and crossbred animals $(33.3 \%)$ or Holsteins and Jerseys (5.5\%).

Average time from birth to separation from the dam was $1.7 \mathrm{~h}$ (range: 0 to $6 \mathrm{~h}$ ), at which point calves received colostrum at a reported amount (mean $\pm \mathrm{SD}$ ) of $3.67 \pm 0.75 \mathrm{~L}$ (range: 2 to 6 ) at the first feeding. Colostrum was delivered mostly by bottle ( $47.1 \%$ of farms) or esophageal tubing $(41.2 \%)$, with nursing the dam $(8.8 \%)$ or a combination of nursing and bottle feeding $(2.9 \%)$ being less popular. A total of 925 calves were sampled on 35 farms for STP analysis, with an overall average of $5.44 \pm 0.72 \mathrm{~g} / \mathrm{dL}$. Of the calves sampled, $22 \%$ had STP $<5.0$, whereas $33.6 \%$ were below $5.2 \mathrm{~g} /$ dL. Farm average STP was $5.44 \pm 0.39$, but $14.3 \%$ of farms averaged $<5.0$ and $25.7 \%$ of farms averaged $<5.2$ $\mathrm{g} / \mathrm{dL}$. Calves were housed individually until $5.1 \pm 3.9 \mathrm{~d}$ of age (range: 0 to $14 \mathrm{~d}$ ), with $25.7 \%$ of farms grouping calves with automated feeding at $\mathrm{d} 1$ of age. Although farm average STP was not found to be significant in the multivariable models discussed below, the cut-points of 5.0 and $5.2 \mathrm{~g} / \mathrm{dL}$ have been previously identified as the most accurate in assessing the success or failure of passive immune transfer in dairy calves (Calloway et al., 2002) and that inadequate transfer increases the relative risk of mortality in these animals (Tyler et al., 1998).

Upon integration into mixed housing, calves were kept in groups of $17.6 \pm 9.8$ animals (range: 5.9 to 60.5 ). The mean per-farm pen size for group housed calves was $71 \pm 36 \mathrm{~m}^{2}$. Pen space allowed per calf was $4.6 \pm 2.0 \mathrm{~m}^{2}$ (range: 1.6 to $11.9 \mathrm{~m}^{2}$ ). Only $17.6 \%$ of producers used an "all-in/all-out" stocking approach in which calf groups were relatively stable with no additional calves entering or leaving the group once the pen had been filled. Much more common ( $82.4 \%$ of farms) was a dynamic stocking approach in which calves were often added or removed from the automated feeder pen as individuals or in small groups. The average age range between the oldest and youngest calf in the group pen was $3.1 \pm 2.0 \mathrm{wk}$ (range: 0.3 to $10 \mathrm{wk}$ ).

Housing Characteristics. Calves were housed primarily in barns that had been retrofitted to operate automated feeding systems $(60.5 \%)$, whereas the remainder $(39.5 \%)$ were housed in newly constructed facilities. Natural ventilation (barns featuring adjustable curtain walls on at least one side) was most common, used on $50 \%$ of the farms, followed by barns with mechanical ventilation (solid wall structures featuring one or more exhaust fans), which was used on $39.5 \%$ of the farms. A smaller proportion of farms used tunnel ventilated barns $(7.9 \%)$ or outdoor facilities (sheltered plastic domes; $2.6 \%$ ). Positive pressure ventilation tubing was present on most farms $(86.8 \%)$, with a small proportion 
of farms $(13.2 \%)$ not using this type of supplemental ventilation. Maximum recorded air speed $(\mathrm{m} / \mathrm{s})$ was $0.32 \pm 0.39$ (range: 0 to 2.84), and measurements followed a clear seasonal pattern, peaking during summer at $0.63 \pm 0.66$ (range: 0 to 3.95 ) and being slowest during winter 2 at $0.14 \pm 0.16$ (range: 0 to 0.81 ).

Pens in this study typically featured a bedding substrate of some type, although this was not always the case. Straw was the most common bedding material, used in 435 of the 558 pens (78\%) in which bedding characteristics were measured. Other bedding materials included cornstalks (68 pens; $12.2 \%$ ), wood shavings (29 pens; $5.2 \%$ ), soybean straw ( 8 pens; $1.4 \%$ ), and sand (3 pens; $0.5 \%$ ). One automated feeding system was installed in a retrofitted swine barn, which housed calves on a slatted metal floor and in which bedding was not used (15 pens; $2.7 \%$ ). Bedding depth was 16.3 $\pm 7.1 \mathrm{~cm}$ (range: $2.5 \mathrm{~cm}$ to $40.6 \mathrm{~cm}$ ). When categorized by bedding type, straw was bedded at the greatest depth $(16.8 \pm 6.9 \mathrm{~cm})$, followed by cornstalks $(16.3 \pm$ $8.1 \mathrm{~cm})$, sand $(16.1 \pm 3.9 \mathrm{~cm})$, soybean straw $(15.1 \pm$ $4.4 \mathrm{~cm})$, and wood shavings $(8.0 \pm 4.0 \mathrm{~cm})$. It should be noted that sand was used as the primary bedding substrate only during summer and was replaced with straw or cornstalks in colder months. Bedding wetness was tested in 547 pens (2,188 individual tests at 4/pen). Most bedding wetness tests scored 0 , or completely dry (1,915 tests, $87.5 \%$ ), with 273 tests detecting at least some level of wetness (score of 1 or greater; 12.5\%). Only 59 samples $(2.7 \%)$ received the highest score for wetness, representing a small proportion of the total samples taken, but 1 or more samples with a wetness score of 4 were detected in 50 pens (9.1\%). The farm average sum of bedding wetness scores was $1.1 \pm 0.9$ (range: 0 to 4.2 ) of a possible maximum of 16 per pen (4 measurements with a maximum value of 4 each).

Feeding Management and Diet Characteristics. When introduced to the automated feeder, calves were started at a daily allowance of $5.4 \pm 2.1 \mathrm{~L}$ (range: 3 to $15 \mathrm{~L}$ ) of milk. This rose to a peak amount of $8.3 \pm$ $2.0 \mathrm{~L}$ (range: 5 to $15 \mathrm{~L}$ ). It took $18 \pm 11.4 \mathrm{~d}$ (range: 0 to $44 \mathrm{~d}$ ) for calves to reach the peak milk allowance. Milk replacer was the most popular liquid diet for calves on these automated feeder farms, and was fed on $68.4 \%$ of farms compared with whole milk (approximately $75 \%$ of the farms used a pasteurizer) supplemented with nutrient balancer on $23.7 \%$ and whole milk alone on $7.9 \%$ of these farms. Fat content in all samples (milk and milk replacer) of the liquid diet $(\mathrm{n}=73)$ was $2.8 \pm$ $0.7 \%$ (range: 1.2 to 4.0 ), protein content was $3.3 \pm 0.7 \%$ (range: 1.9 to 5.1 ), and TS were $12.2 \pm 1.9 \%$ (range: 11.1 to 18.0 ). For only those farms using milk replacer, fat content was $2.4 \pm 0.5 \%$ (range: 1.2 to 3.7 ), protein was $3.1 \pm 0.7 \%$ (range: 1.9 to 5.1 ), and TS were 12.0 $\pm 2.2 \%$ (range: 7 to 18 ). Farms feeding supplemented whole milk had fat content of $3.4 \pm 0.6 \%$ (range: 1.7 to 4.0 ), protein of $3.8 \pm 0.4 \%$ (range: 3.2 to 4.6 ), and TS of $12.8 \pm 1.1 \%$ (range: 10.3 to 14.3 ). Farms using whole milk alone had fat content of $3.5 \pm 0.3 \%$ (range: 3.0 to 3.9 ), protein of $3.4 \pm 0.3 \%$ (range: 3.0 to 3.9 ), and TS of $12.0 \pm 0.5 \%$ (range: 11.0 to 12.6 ). The generally gradual weaning period lasted $12.9 \pm 7.7 \mathrm{~d}$ (range: 3 to $42 \mathrm{~d}$ ) from first reduction to complete removal from a liquid diet. Farms began weaning calves from the liquid diet at $44.5 \pm 6.9 \mathrm{~d}$ of age (range 32 to $60 \mathrm{~d}$ ) and time on the feeder of $39.3 \pm 6.3 \mathrm{~d}$ (range: 20 to $59 \mathrm{~d}$ ). Calves were completely cut off from the feeder at $56.8 \pm 9.0 \mathrm{~d}$ of age (range: 40 to $86 \mathrm{~d}$ ) and $52.1 \pm 7.5 \mathrm{~d}$ (range: 40 to $79 \mathrm{~d}$ ) on the feeder. Weaned and preweaned calves were housed together in the same pen on $61.1 \%$ of farms, whereas $38.9 \%$ of producers removed animals on the day of weaning.

Bacterial contamination was present in many of the milk samples. Approximately $28 \%$ of the tube-end and $15 \%$ of the mixing tank samples were $>10,000 \mathrm{cfu} / \mathrm{mL}$ for coliform count and $68 \%$ of the tube end and $32 \%$ of the mixing tank samples were $>100,000 \mathrm{cfu} / \mathrm{mL}$ for SPC. The median farm average for coliform count was $10,430 \mathrm{cfu} / \mathrm{mL}$ (IQR 233,111; range 45 to $28,517,000$ ) in the feeder tube end and $336 \mathrm{cfu} / \mathrm{mL}$ (IQR 28,689; range 0 to $25,621,330$ ) in the mixing tank. The median for SPC was 2,566,867 cfu/mL (IQR 15,860,194; range $6,668$ to $82,825,000)$ in the feeder tube end and 166,916 (IQR 2,066,782; range 125 to $59,396,100$ ) in the mixing tank.

Health Score Frequencies. Table 1 shows the distribution frequencies for each of the health scores measured on farm. For all health scores, the majority of calves were scored as 0 or apparently healthy. More calves were categorized as having abnormal or high-abnormal hide dirtiness scores (41.9 and $9.4 \%$ of animals, respectively) than any other health score. Only 2 calves were dead (attitude score of 4) in the pens observed on any visit day. Of those calves that scored $\mathrm{a} \geq 2$ on any health score category, 550 animals (5.4\% of all animals scored) had a rectal temperature above $39.4^{\circ} \mathrm{C}$, which is generally consistent with morbidity rates of group housed calves observed elsewhere (Le Neindre, 1993).

\section{Risk Factor Analysis}

A maximum of 15 variables in the univariable analyses met the criteria for inclusion in the multivariable models $(P<0.3)$ for each of the separate health outcomes (Table 2). Certain variables were consistently significant across all health score categories, particularly the season of measurement, stocking characteristics (number of calves per group, space per calf), feeding 
strategy, and bacterial measurement category. Highly correlated variables (e.g., bacterial count category in the tube and mixing tank) were reduced to a single representative variable in the multivariable analysis to reduce the detrimental effect of highly collinear variables on the final model. The multivariable models (Table 3) detected significant associations between several management factors and measured health outcomes in dairy calves. Because health scores were only measured approximately every $60 \mathrm{~d}$, a lack of sensitivity or misclassification bias for health outcomes (especially fever) is likely present in the current study.

Feeding Management. We found a negative association between the peak milk allowance to calves $(\mathrm{L} /$ calf per $\mathrm{d})$ and the apparent point prevalence of diarrhea estimated as hide dirtiness score. Each additional liter of milk allowed was associated with a $12 \%$ decrease $(P<0.001)$ in the odds of calves receiving a high score for hide dirtiness (i.e., a higher milk allowance was associated with cleaner calves). It has been shown previously that the amount of milk fed to calves has significant effects on health and development in the preweaning period. Although feeding calves more milk in this period has been shown to positively affect growth rate (Khan et al., 2007), there are concerns that high milk allowances may be related to worsening fecal scores and more days with diarrhea (Quigley et al., 2006). The issues observed in that study may be more related to the concentration of the milk fed rather than the amount and it is important to distinguish that loose fecal material and pathogenic diarrhea are not the same thing. In addition, Liang et al. (2015) found a poor association between visual appraisal of fecal material and DM percentage of feces. The majority of studies show that the rate of enteric infection is not increased for calves fed high milk allowances (Chua et al., 2002; Jasper and Weary, 2002) and in some cases the rate is reduced (Khan et al., 2007). Nutritional insufficiency has a suppressive effect on immune function (Nonnecke et al., 2003; Ballou, 2012), thus feeding more milk may positively affect the ability of a calf to combat infection.

Additionally, the speed at which a feeding plan reached peak milk allowance (L/calf per d) appeared to be broadly important across almost all of the recorded health scores. Each additional day taken to reach the peak milk allowance was associated with an increase in the odds of calves receiving a higher attitude score (1.3\%/unit increased risk; $P=0.023)$, ear score $(2.2 \%$; $P=0.039)$, eye score $(2.2 \% ; P=0.039)$, and hide dirtiness score $(1.9 \% ; P=0.006)$, and in the odds of a calf being categorized as having a fever $(2.5 \% ; P=$ 0.002 ). Relatively little research is available comparing the pattern of liquid diet increases with health outcomes in dairy calves, but it has been shown that higher allowances in early life can provide the calf with approximately twice the nutrient intake as those fed the traditional limited diet (Khan et al., 2011), which is likely to have similar immune function benefits to those seen in calves fed a high volume of milk throughout the preweaning period. In a recent observational study, de Passillé et al. (2016) reported that calves that drank a larger quantity of milk during the first $4 \mathrm{~d}$ after birth had a reduced risk of becoming ill in the subsequent period. Our results suggest that there may be an advantage to calf health by increasing the daily milk allowance rapidly rather than gradually.

Milk Composition. We found a relationship between the farm-average fat content of the milk and calf

Table 1. Distribution frequencies of health scores for attitude, ear, eye, nasal, hide dirtiness, and fever in preweaned dairy calves housed in 38 farm with automated calf feeders in the Upper Midwest United States

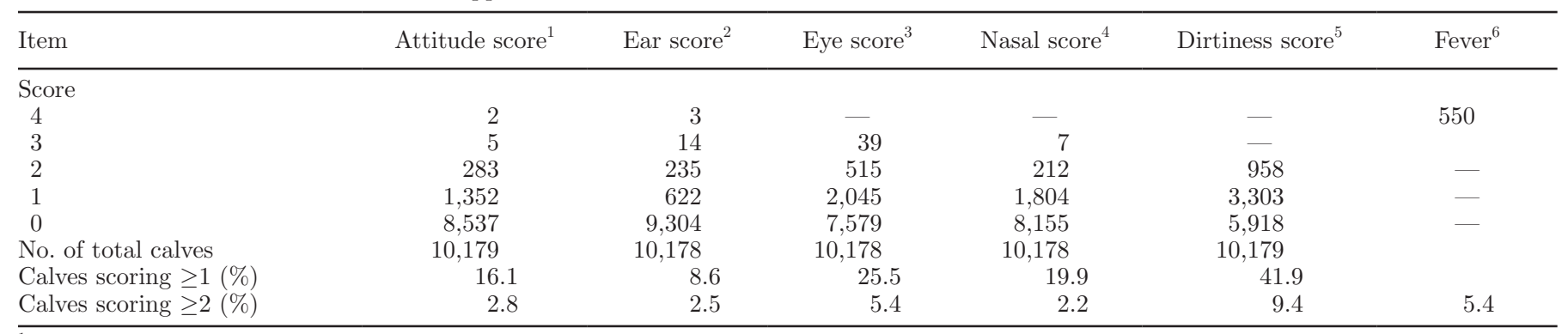

${ }^{1}$ Attitude score $=0$ (normal), 1 (quiet, dull), 2 (depressed), 3 (nonresponsive), and 4 (dead).

${ }^{2}$ Ear score $=$ ear position 0 (normal), 1 (unilateral ear droop), 2 (slight bilateral ear droop), 3 (severe bilateral ear droop), and 4 (head tilt).

${ }^{3}$ Eye score $=0$ (normal), 1 (small amount of ocular discharge), 2 (moderate amount of bilateral discharge), and 3 (heavy ocular discharge).

${ }^{4}$ Nasal score $=0$ (normal serous discharge), 1 (small amount of unilateral cloudy discharge), 2 (bilateral, cloudy or excessive discharge), and 3 (copious bilateral mucopurulent discharge).

${ }^{5}$ Hide dirtiness score $=$ dirtiness score of the perianal region, tail underside, and pins of each calf: 0 (normal), 1 (evidence of loose or abnormal fecal consistency), 2 (significant evidence of watery diarrhea).

${ }^{6}$ Confirmed high rectal temperature $\left(>39.4^{\circ} \mathrm{C}\right)$. 
RISK FACTORS FOR DISEASE IN AUTO CALF FEEDERS

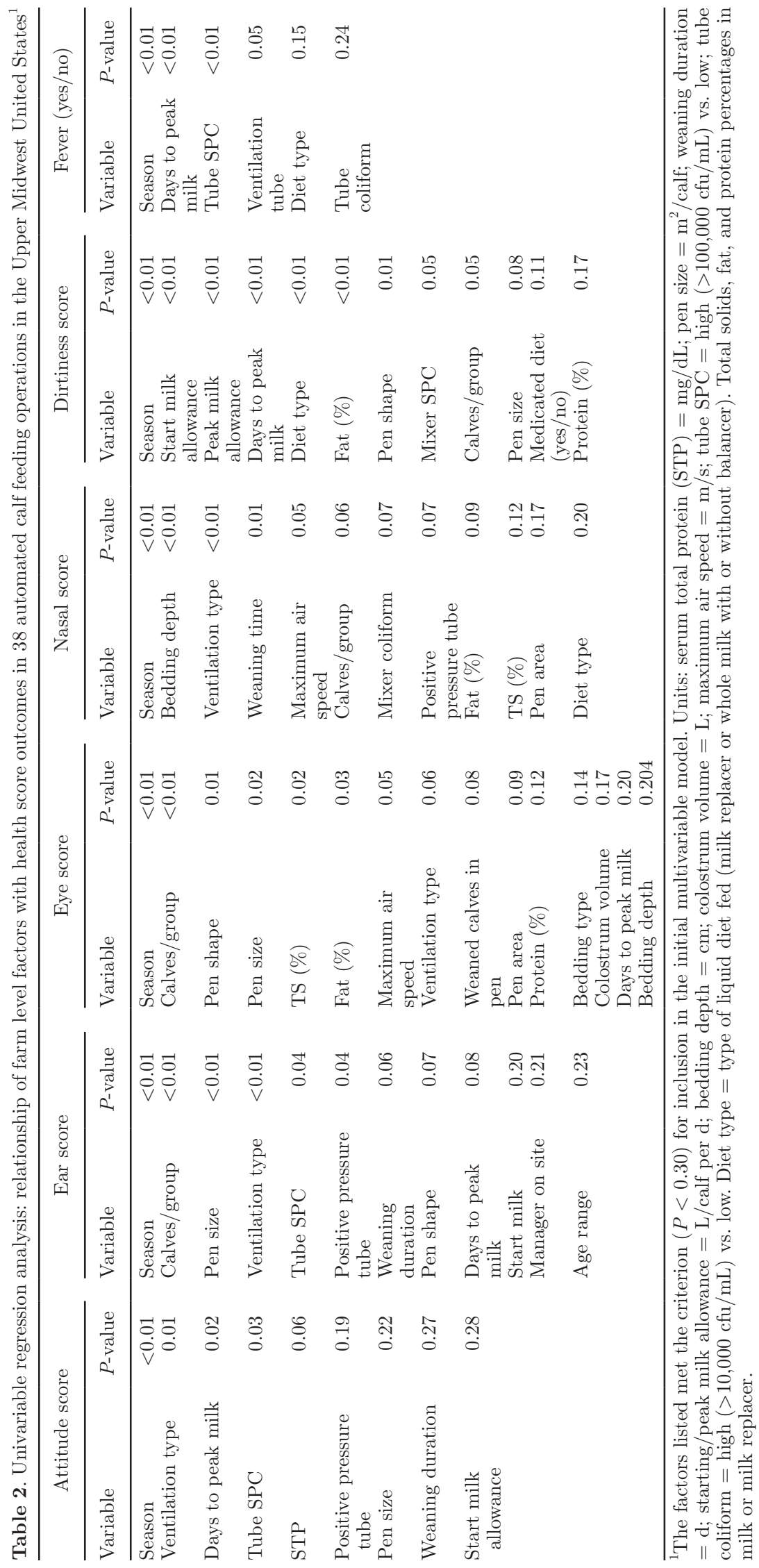


Table 3. Multivariable association of calf health score categories with farm-level variables [odds ratio (OR) estimates and $95 \% \mathrm{CI}]^{1}$ on 38 farms in the Upper Midwest United States using automated calf feeders

\begin{tabular}{|c|c|c|c|c|c|}
\hline$\frac{\text { Health score }}{\text { Attitude score }}$ & $\begin{array}{l}\text { Variable } \\
\text { Season }\end{array}$ & $\frac{\text { OR estimate }}{-}$ & $\begin{array}{r}P \text {-value } \\
<0.001\end{array}$ & \multicolumn{2}{|c|}{$95 \% \mathrm{CI}$} \\
\hline & Fall 1 & 1.05 & - & 0.76 & 1.45 \\
\hline & Winter 1 & 0.98 & - & 0.76 & 1.26 \\
\hline & Summer 1 & 0.80 & - & 0.62 & 1.03 \\
\hline & Fall 2 & $0.74^{\mathrm{a}}$ & & 0.58 & 0.95 \\
\hline & Winter 2 & Referent & - & - & - \\
\hline & Spring 2 & 0.89 & - & 0.65 & 1.23 \\
\hline & Days to peak milk allowance & 1.01 & 0.024 & 1.00 & 1.03 \\
\hline \multirow[t]{6}{*}{ Ear score } & Season & - & $<0.001$ & - & - \\
\hline & Fall 1 & 1.44 & - & 0.88 & 2.36 \\
\hline & Winter 1 & $1.87^{\mathrm{a}}$ & - & 1.26 & 2.78 \\
\hline & Spring 1 & 0.99 & - & 0.67 & 1.48 \\
\hline & Summer 1 & 0.86 & - & 0.57 & 1.29 \\
\hline & Fall 2 & 1.29 & - & 0.88 & 1.90 \\
\hline \multirow[t]{12}{*}{ Eye score } & Season & - & $<0.001$ & - & - \\
\hline & Fall 1 & $0.22^{\mathrm{a}}$ & - & 0.13 & 0.38 \\
\hline & Winter 1 & $0.42^{\mathrm{a}}$ & - & 0.29 & 0.60 \\
\hline & Spring 1 & $0.42^{\mathrm{a}}$ & - & 0.30 & 0.60 \\
\hline & Summer 1 & 0.99 & - & 0.71 & 1.38 \\
\hline & Fall 2 & $1.74^{\mathrm{a}}$ & - & 1.26 & 2.41 \\
\hline & Winter 2 & Referent & - & - & - \\
\hline & Spring 2 & $0.41^{\mathrm{a}}$ & - & 0.26 & 0.66 \\
\hline & Pen shape (rectangle vs. square) & 0.46 & 0.011 & 0.26 & 0.84 \\
\hline & Stocking density $\left(\mathrm{m}^{2} /\right.$ calf $)$ & 0.92 & 0.007 & 0.87 & 0.98 \\
\hline & Average fat $(\%)$ of liquid diet & 1.62 & 0.006 & 1.15 & 2.29 \\
\hline & Days to peak milk allowance & 1.02 & 0.04 & 1.00 & 1.04 \\
\hline \multirow[t]{2}{*}{ Nasal score } & Season & - & $<0.001$ & - & - \\
\hline & Fall 1 & $0.05^{\mathrm{a}}$ & - & 0.03 & 0.09 \\
\hline \multirow{8}{*}{ Hide dirtiness score } & Spring 1 & $0.43^{\mathrm{a}}$ & - & 0.33 & 0.55 \\
\hline & Summer 1 & $0.54^{\mathrm{a}}$ & - & 0.42 & 0.69 \\
\hline & Fall 2 & $0.76^{\mathrm{a}}$ & - & 0.59 & 0.97 \\
\hline & Winter 2 & Referent & - & - & - \\
\hline & Spring 2 & $0.47^{\mathrm{a}}$ & - & 0.34 & 0.65 \\
\hline & Peak milk allowance $(\mathrm{L})$ & 0.88 & $<0.001$ & 0.82 & 0.95 \\
\hline & Days to peak milk allowance & 1.02 & 0.006 & 1.01 & 1.03 \\
\hline & Number of calves/group & 0.99 & 0.048 & 0.97 & 1.00 \\
\hline \multirow[t]{11}{*}{ Fever (yes/no) } & Season & & $<0.001$ & & \\
\hline & Fall 1 & $0.34^{\mathrm{a}}$ & - & 0.18 & 0.62 \\
\hline & Winter 1 & $0.51^{\mathrm{a}}$ & - & 0.33 & 0.78 \\
\hline & Spring 1 & $0.42^{\mathrm{a}}$ & - & 0.28 & 0.64 \\
\hline & Summer 1 & $0.51^{\mathrm{a}}$ & - & 0.34 & 0.76 \\
\hline & Fall 2 & 0.83 & - & 0.57 & 1.22 \\
\hline & Winter 2 & Referent & - & - & - \\
\hline & Spring 2 & 0.62 & - & 0.36 & 1.06 \\
\hline & Days to peak milk allowance & 1.03 & 0.002 & 1.01 & 1.04 \\
\hline & Tube SPC category (high vs. low) ${ }^{2}$ & 1.82 & $<0.001$ & 1.35 & 2.44 \\
\hline & Positive pressure ventilation tube present & 1.81 & 0.025 & 1.08 & 3.03 \\
\hline
\end{tabular}

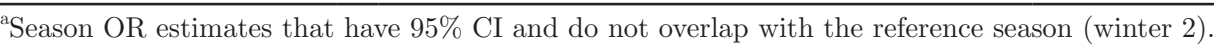

${ }^{1}$ Odds ratios predict increase in health score per unit of increase in the factor of interest.

${ }^{2}$ Tube SPC category $=$ sample taken at time of health scoring: $<100,000 \mathrm{cfu} / \mathrm{mL}=$ low; $>100,000 \mathrm{cfu} / \mathrm{mL}=$ high. 
health, whereby each additional percentage point of fat content was associated with a $62.4 \%$ increase in the odds of a high eye score $(P=0.006)$. However, farm-average fat content was not associated with other health score measures. Previous work has shown no effect of milk replacer fat content on health outcomes in bull calves when carbohydrate levels were maintained at reasonable concentrations (Tikofsky et al., 2001). The variability in the liquid diet composition appeared to be large for calves raised on automated feeding systems in the current study. The lack of consistency, particularly on those farms feeding milk replacer (rather than whole milk), is not necessarily indicative of a mechanical issue in automated feeding systems and is likely indicative of management issues, such as machine calibration and management, which were not measured in the current study. It is also worth noting that the average component analysis was conducted on 2 samples per farm; therefore, a more in-depth investigation of how machine management affects outcomes related to nutritional concentration, as well as how this variation affects calf health on automated feeding systems, is warranted.

The significant relationship between calf health and feeding management is broadly consistent with previous work; feeding calves a higher volume of liquid in the preweaning period appears to be an important factor in supporting positive health outcomes. More work is necessary to determine how milk intake patterns in the very early stages of life affect calf health, particularly how calves cope with rapid increases in milk allowance in the first few days on the feeder.

Bacterial Contamination. Feeding large amounts of milk benefits calf growth and health, but only if that milk is safe for consumption; contaminated liquid represents a major risk to calves (Lorenz et al., 2011). We chose to categorize our samples based on recommendations that bacterial contamination of milk fed to calves be limited to a maximum of $100,000 \mathrm{cfu} / \mathrm{mL}$ in SPC and to $10,000 \mathrm{cfu} / \mathrm{mL}$ for coliform bacteria (McGuirk and Collins, 2004). These specific thresholds have not been extensively investigated in controlled studies, but can be considered industry goals. In the current study, SPC above the $100,000 \mathrm{cfu} / \mathrm{mL}$ limit increased the odds of a higher attitude score by $20.7 \%(P=0.033)$, a higher ear score by $31.8 \%(P=0.01)$, and the odds of a calf being detected with fever by $81.5 \%(P<0.001)$.

Although milk replacer has relatively low risk for contamination under ideal conditions (McGuirk, 2008), the automated feeding system adds several new potential reservoirs of bacteria, in the mixing tank and tube, where liquid milk is frequently present, most obviously, but also in the milk powder storage area and in/on the nipple from which calves nurse. Environmental temperature is an important factor influencing the rate of proliferation of bacterial cells, and increased contamination of colostrum has been detected in warmer months (Fecteau et al., 2002). Automated feeders are often installed in heated rooms to avoid freezing, but a combination of this heat, a lack of ventilation in the feeder housing, and any errors in machine installation or maintenance that allow milk to pool in the feeder mixing tank or tubing could contribute to bacterial growth.

The majority of these feeders are designed to run an automated cleaning function in the mixing tank, while requiring user activation of processes or manual cleaning to maintain sanitary conditions in the machine tubing, internal hardware, and nipple. Cleaning functions of automated feeders are not well understood, and although more frequent automated and manual cleaning of the machines has been shown to be associated with reduced bacterial contamination in milk, certain cleaning functions may loosen built-up biofilms and increase bacterial content in the short term (Dietrich et al., 2015). A more robust analysis of automated feeder cleaning is needed, but it is likely that a lack of training and awareness on how to properly maintain the machines, as well as failure to adequately monitor contamination, are likely to affect bacterial counts. For farms feeding waste milk, storage and refrigeration add steps to the process of providing an uncontaminated diet to preweaned calves, though these risks could likely be reduced by pasteurization.

Although many operations provided calves with a diet that met recommendations for bacterial counts, highly contaminated samples were taken from multiple sources (mixing tanks and tubes) on several operations in the current study. The relative frequency of contamination is cause for major concern regarding the intake of pathogens by calves on automated feeders.

Group Management. A larger group size was associated with an increased odds of a higher nasal score. For each additional calf in the pen, the odds of a higher nasal score rose by $1.1 \%(P=0.044)$. However, the association was reversed for the hide dirtiness score, and each additional calf in the group was an associated with a $1.3 \%$ decrease in the odds of a higher hide dirtiness score $(P=0.048)$. These odds ratios were small, and although significant, the biological consequences of such odds might not be very great. Svensson et al. (2003) found that larger group sizes (12 to 18 animals) increased the risk of respiratory disease but not of diarrhea, an outcome that is supported by our results. A relationship between group size and calf health has been shown, but it has been hypothesized that these effects may be minimized by other management decisions that can alter health outcomes even on farms with larger groups (Rushen et al., 2008). It is important to 
note that the average group size in the current study was 17.8 calves and few farms stocked calves in large groups (25 to 30 animals). This might have limited our ability to detect a stronger relationship between group size and calf health. Previous studies have reported that calves can be housed successfully in small groups (6 to 8 animals), but several studies have shown an increase in morbidity and mortality for calves housed in large groups compared with those housed individually or in smaller groups (Losinger and Heinrichs, 1997). In multiple Swedish studies, calves housed in larger groups (12 to 18 animals) had a higher incidence of respiratory disease and diarrhea than those housed in smaller groups (6 to 8 animals; Svensson et al., 2003; Svensson and Liberg, 2006).

In a group housing system, calf health may also be affected by space availability (stocking density) independent of group size. In the current study, a stronger relationship was observed between space per calf and health scores than between group size and health scores; for every additional square meter of space allowed per calf there was a $10.4 \%$ decrease in the odds of receiving a higher ear score $(P=0.006)$ and a $7.7 \%$ decrease in the odds of a higher eye score $(P=0.008)$. These results are consistent with previous work demonstrating that increased stocking density was associated with adverse health events in calves (Bendali et al., 1999). In adult cattle, a higher stocking density increases the pathogen load in a pen (Grooms and Kroll, 2015) and stocking density has been shown to have a greater effect on airborne pathogen density than ventilation (Nardell et al., 1991), both effects that one would anticipate holding true for young stock as well.

Pen and Barn Characteristics. The effects of stocking density are potentially intertwined with several other aspects of barn design. In the current study we found an association between the eye score and the pen shape, in which a rectangular pen shape (pens at least 2.5 times longer than they were wide) was associated with a $53.7 \%$ decrease in the odds of a higher eye score when compared with a square pen $(P=0.011)$. Longer, narrower pens (particularly those with a positive pressure ventilation tube running above them) may benefit from a greater effect of ventilation on airborne pathogen density. The distance fresh air is able to travel from a ventilation tube is limited to 3 to $5 \mathrm{~m}$ on either side (Nordlund, 2008), so in certain circumstances a narrower pen design may help to ensure that the entire calf pen is properly ventilated. As calf group housing increases in popularity, it would likely be beneficial to further explore the effect that pen shape may have on calf health and behavior, as well as on ventilation system effectiveness.
Regardless of pen shape, proper ventilation of calf housing areas is critical in the maintenance of sanitary facilities; the airborne pathogen load can have a dramatic effect on calf health. In a previous study of individually housed calves in naturally ventilated Midwest US barns, a positive association was reported between the total $\mathrm{cfu} / \mathrm{m}^{3}$ and the prevalence of respiratory disease (Lago et al., 2006). Calf areas can be difficult to properly ventilate, particularly in winter when the need to balance between air movement and cold stress in calves can result in poorly ventilated areas (Lago et al., 2006). If calves have sufficient bedding in which to nest, then more air movement is possible without cooling calves. It has been recommended that calves be housed on deep straw during winter months so that ventilation systems can continue to operate (Nordlund, 2008).

Positive pressure ventilation systems are frequently recommended for both naturally and mechanically ventilated calf barns to ensure that sufficient fresh air is reaching the animals, even during times of inclement weather or temperature change (Nordlund, 2008). Our observations of automated feeder facilities are consistent with this recommendation, and barns that did not have a positive pressure ventilation system in use were associated with an $80.6 \%$ increase in the odds of a calf being detected with fever on the day of the visit $(P=$ $0.025)$.

\section{Seasonal Patterns}

Season was highly significant in every individual model, and comparisons of seasonal effects indicate that certain seasons were consistently worse for calf health outcomes than others. Winter 2 was associated with higher attitude scores than spring 1 and fall 2, whereas winter 1 was also associated with higher ear scores. Fall 2 was associated with higher eye scores, and winter 2 was associated with higher nasal scores, hide dirtiness scores, and more animals detected with fever. It is important to note that when the $95 \%$ confidence intervals are considered, the clarity of relationship between season and health is somewhat reduced; wide confidence intervals for ear score, in particular, make it difficult to definitively conclude that winter 1 was different from any season except winter 2 .

The relationships indicate that fall and winter scores were most typically associated with worse health outcomes, which is generally consistent with previous findings. Leech et al. (1968) found that mortality rates were higher in calves during the winter than in the summer. Additional work in other locations has shown a similar trend of increased mortality in winter (Martin et al., 1975; Svensson et al., 2006), even when overall mortality 
rates remain low throughout the year (Waltner-Toews et al., 1986a). Changes in temperature and precipitation are known to have an effect on calf health and survival (Martin et al., 1975), but additional factors likely play a part in these seasonal differences, particularly management decisions that account for changing calf needs in difficult seasons. Failure to provide calves with appropriate nesting material and increased nutrient intake to meet increased maintenance demands for thermogenesis, immune function and growth, as well as decisions surrounding barn ventilation rates, are among those factors likely to affect the ability of calves to thrive during challenging times such as cold winters.

\section{CONCLUSIONS}

This study identified several farm-level risk factors that were associated with worse calf health; aspects of the feeding plan, group size and stocking management, ventilation of the calf barn, and bacterial contamination of the liquid diet were all associated with health scores. Many had small odds ratios and might not have much biological effect. However, it seems that particular attention should be paid to the bacterial contamination of liquid diet and to the speed at which calves reach peak milk allowance as these factors appeared across several health score categories. Although identifying these risk factors is a first step in understanding the intricacies of automated calf feeder use, it should be noted that more research is needed to better understand the causal relationships between the factors discussed and calf health outcomes.

\section{ACKNOWLEDGMENTS}

We thank all the dairy producers who participated in the study. In addition, we thank Luis Espejo (St. Augustine, FL) for help with statistical analysis. We also thank the various students at the University of Minnesota who helped with data entry (Nathan Bos, Kelly Froehlich, Andrew Hetke, Andrew Plumski, and Michael Schmitt). This project was supported by Agriculture and Food Research Initiative competitive grant no. 2012-67021-19280 from the USDA National Institute of Food and Agriculture (Washington, DC).

\section{REFERENCES}

Ballou, M. A. 2012. Immune responses of Holstein and Jersey calves during the preweaning and immediate postweaned period when fed varying planes of milk replacer. J. Dairy Sci. 95:7319-7330. https://doi.org/10.3168/jds.2012-5970.
Bendali, F., M. Sanaa, H. Bichet, and F. Schelcher. 1999. Risk factors associated with diarrhoea in newborn calves. Vet. Res. 30:509-522. https://hal.archives-ouvertes.fr/hal-00902591.

Callan, R. J., and F. B. Garry. 2002. Biosecurity and bovine respiratory disease. Vet. Clin. North Am. Food Anim. Pract. 18:57-77. https://doi.org/10.1016/S0749-0720(02)00004-X.

Calloway, C. D., J. W. Tyler, R. K. Tessman, D. Hostetler, and J. Holle. 2002. Comparison of refractometers and test endpoints in the measurement of serum protein concentration to assess passive transfer status in calves. J. Am. Vet. Med. Assoc. 221:1605-1608. https://doi.org/10.2460/javma.2002.221.1605 http://dx.doi.

Canadian Dairy Research Project. 2011. Stall Wetness Cluster Project. Accessed Oct. 1, 2012. https://www.dairyresearch.ca/pdf/2dstall\%20bedding\%20wetness\%20sop_221210.pdf.

Chua, B., E. Coenen, D. J. van, and D. M. Weary. 2002. Effects of pair versus individual housing on the behavior and performance of dairy calves. J. Dairy Sci. 85:360-364. https://doi.org/10.3168/ jds.S0022-0302(02)74082-4.

Costa, J. H. C., R. K. Meagher, M. A. G. Von Keyserlingk, and D. M. Weary. 2015. Early pair housing increases solid feed intake and weight gains in dairy calves. J. Dairy Sci. 98:6381-6386. https:// doi.org/10.3168/jds.2015-9395.

de Passillé, A. M., M. Rabeyrin, and J. Rushen. 2016. Associations between milk intake and activity in the first days of a calf's life and later growth and health. Appl. Anim. Behav. Sci. 175:2-7. https:// doi.org/10.1016/j.applanim.2014.10.002.

De Paula Vieira, A., M. A. G. Von Keyserlingk, and D. M. Weary. 2010. Effects of pair versus single housing on performance and behavior of dairy calves before and after weaning from milk. J. Dairy Sci. 93:3079-3085. https://doi.org/10.3168/jds.2009-2516.

Dietrich, A. M., W. A. Knauer, S. A. Godden, C. S. Petersson-Wolfe, and R. E. James. 2015. Factors associated with aerobic plate count, coliform count, and log reduction of bacteria in automated calf feeders. J. Dairy Sci. 98(E-Suppl. 2):214.

Fecteau, G., P. Baillargeon, R. Higgins, J. Paré, and M. Fortin. 2002. Bacterial contamination of colostrum fed to newborn calves in Québec dairy herds. Can. Vet. J. 43:523-527.

Grooms, D. L., and L. A. K. Kroll. 2015. Indoor confined feedlots. Vet. Clin. North Am. Food Anim. Pract. 31:295-304. https://doi. org/10.1016/j.cvfa.2015.03.007.

Heinrichs, A. J., B. S. Heinrichs, O. Harel, G. W. Rogers, and N. T. Place. 2005. A prospective study of calf factors affecting age, body size, and body condition score at first calving of dairy heifers. J. Dairy Sci. 88:2828-2835. https://doi.org/10.3168/jds.S00220302(05) 72963-5.

Jasper, J., and D. M. Weary. 2002. Effects of ad libitum milk intake on dairy calves. J. Dairy Sci. 85:3054-3058. https://doi.org/10.3168/ jds.S0022-0302(02)74391-9.

Kack, M., and J. Ziemerink. 2010. Benefits, function and operation of computer-controlled calf feeders. In First North American Conference on Precision Dairy Management 2010, Toronto, Canada. Accessed Apr. 14. 2017. http://precisiondairy.com/proceedings/ s4kack.pdf.

Khan, M. A., H. J. Lee, W. S. Lee, H. S. Kim, K. S. Ki, T. Y. Hur, G. H. Suh, S. J. Kang, and Y. J. Choi. 2007. Structural growth, rumen development, and metabolic and immune responses of Holstein male calves fed milk through step-down and conventional methods. J. Dairy Sci. 90:3376-3387. https://doi.org/10.3168/ jds.2007-0104.

Khan, M. A., D. M. Weary, and M. A. G. von Keyserlingk. 2011. Invited review: Effects of milk ration on solid feed intake, weaning and performance in dairy heifers. J. Dairy Sci. 94:1071-1081. https://doi.org/10.3168/jds.2010-3733.

Kung, L., S. Demarco, L. N. Siebenson, E. Joyner, G. F. W. Haenlein, and R. M. Morris. 1997. An evaluation of two management systems for rearing calves fed milk replacer. J. Dairy Sci. 80:25292533. https://doi.org/10.3168/jds.S0022-0302(97)76206-4.

Lago, A., S. M. McGuirk, T. B. Bennett, N. B. Cook, and K. V. Nordlund. 2006. Calf respiratory disease and pen microenvironments in naturally ventilated calf barns in winter. J. Dairy Sci. 89:40144025. https://doi.org/10.3168/jds.S0022-0302(06)72445-6. 
Le Neindre, P. 1993. Evaluating housing systems for veal calves. J. Anim. Sci. 71:1345-1354. https://doi.org/10.2527/1993.7151345x.

Leech, F. B., W. D. Macrea, and D. W. Menzies. 1968. Calf wastage and husbandry in Britain 1962-1963. Anim. Dis. Surveys Re. No. 5, Her Majesty's Stationery Office, London, UK.

Liang, Y., J. A. Carroll, and M. A. Ballou. 2015. Plane of milk replacer nutrition influences the resistance to an oral Citrobacter freundii opportunistic infection in Jersey calves at 10 days of age. J. Dairy Sci. 98(Suppl. 2):743

Lorenz, I., J. F. Mee, B. Earley, and S. J. More. 2011. Calf health from birth to weaning. I. General aspects of disease prevention. Ir. Vet. J. 64:10-18. https://doi.org/10.1186/2046-0481-64-10.

Losinger, W. C., and A. J. Heinrichs. 1997. Management practices associated with high mortality among preweaned dairy heifers. J. Dairy Res. 64:1-11. https://doi.org/10.1017/S0022029996001999.

Martin, S. W., C. W. Schwabe, and C. E. Franti. 1975. Dairy cal mortality rate: the association of daily meteorological factors and calf mortality. Can. J. Comp. Med. 39:377-388.

McGuirk, S. M. 2008. Disease management of dairy calves and heifers. Vet. Clin. North Am. Food Anim. Pract. 24:139-153. https://doi. org/10.1016/j.cvfa.2007.10.003.

McGuirk, S. M., and M. Collins. 2004. Managing the production, storage and delivery of colostrum. Vet. Clin. North Am. Food Anim. Pract. 20:593-603. https://doi.org/10.1016/j.cvfa.2004.06.005.

Miller-Cushon, E. K., and T. J. DeVries. 2016. Effect of social housing on the development of feeding behavior and social feeding preferences of dairy calves. J. Dairy Sci. 99:1406-1417. https://doi. org/10.3168/jds.2015-9869.

Nardell, E. A., J. Keegan, S. A. Cheney, and S. C. Etkind. 1991 Airborne infection: Theoretical limits of protection achievable by building ventilation. Am. Rev. Respir. Dis. 144:302-306. https:// doi.org/10.1164/ajrccm/144.2.302.

Nonnecke, B. J., M. R. Foote, J. M. Smith, B. A. Pesch, and M. E. Van Amburgh. 2003. Composition and functional capacity of blood mononuclear leukocyte populations from neonatal calves on standard and intensified milk replacers. J. Dairy Sci. 86:3592-3604. https://doi.org/10.3168/jds.S0022-0302(03)73965-4.

Nordlund, K. V. 2008. Practical considerations for ventilating calf barns in winter. Vet. Clin. Food. Anim. 24:41-54. https://doi. org/10.1016/j.cvfa.2007.10.006.

Quigley, J. D., T. A. Wolfe, and T. H. Elsassert. 2006. Effects of additional milk replacer feeding on calf health, growth, and selected blood metabolites in calves. J. Dairy Sci. 89:207-216. https://doi org/10.3168/jds.S0022-0302(06)72085-9.

Rushen, J., A. M. de Passillé, M. A. G. von Keyserlingk, and D. M. Weary. 2008. Housing for growing animals. Pages 181-210 in The Welfare of Cattle. C. Phillips, ed. Springer, Dordrecht, the Netherlands.

Svensson, C., and P. Liberg. 2006. The effect of group size on health and growth rate of Swedish dairy calves housed in pens with automatic milk-feeders. Prev. Vet. Med. 73:43-53. https://doi. org/10.1016/j.prevetmed.2005.08.021.

Svensson, C. A. Linder, and S. O. Olsson. 2006. Mortality in Swedish dairy calves and replacement heifers. J. Dairy Sci. 89:4769-4777. https://doi.org/10.3168/jds.S0022-0302(06)72526-7.

Svensson, C., K. Lundborg, U. Emanuelson, and S. O. Olsson. 2003 Morbidity in Swedish dairy calves from birth to 90 days of age and individual calf-level risk factors for infectious diseases. Prev. Vet. Med. 58:179-197. https://doi.org/10.1016/S0167-5877(03)00046-1.

Tikofsky, J. N., M. E. Van Amburgh, and D. A. Ross. 2001. Effect of varying carbohydrate and fat content of milk replacer on body composition of Holstein bull calves. J. Anim. Sci. 79:2260-2267. https://doi.org/10.2527/2001.7992260x.

Tyler, J. W., D. D. Hancock, S. R. Wiksie, S. L. Holler, J. M. Gay, and C. C. Gay. 1998. Use of serum protein concentration to predict mortality in mixed-source dairy replacement heifers. J. Vet. Intern. Med. 12:79-83. https://doi.org/10.1111/j.1939-1676.1998. tb02099.x.

USDA. 2017. Dairy 2014. Health and Management Practices on U.S. Dairy Operations. USDA-APHIS-VS-CEAH-NAHMS. Fort Collins, CO. In press.

Waltner-Toews, D., S. Martin, and A. Meek. 1986a. Dairy calf management, morbidity and mortality in Ontario Holstein herds. II. Age and seasonal patterns. Prev. Vet. Med. 4:125-135. https://doi org/10.1016/0167-5877(86)90018-8.

Waltner-Toews, D., S. Martin, and A. Meek. 1986b. Dairy calf management, morbidity and mortality in Ontario Holstein herds. III. Association of management with morbidity. Prev. Vet. Med. 4:137-158. https://doi.org/10.1016/0167-5877(86)90019-X.

Waltner-Toews, D., S. Martin, and A. Meek. 1986c. Dairy calf management, morbidity and mortality in Ontario Holstein herds. IV. Association of management with mortality. Prev. Vet. Med. 4:159 171. https://doi.org/10.1016/0167-5877(86)90020-6. 